\title{
Expression of behavioral sensitization to ethanol by DBA/2J mice: the role of NMDA and non-NMDA glutamate receptors
}

Received: 16 June 2002 / Accepted: 7 January 2003 / Published online: 1 April 2003

(C) Springer-Verlag 2003

\begin{abstract}
Rationale: Behavioral sensitization has been accorded a central role in contemporary theories of drug addiction. Accordingly, a substantial effort has been made to determine the processes mediating sensitization to psychostimulants. However, few studies have examined the mechanisms underlying sensitization to ethanol. Objectives: Experiments were conducted to assess the role of $N$-methyl-D-aspartate (NMDA) and non-NMDA glutamate receptors in expression of sensitization to ethanol's locomotor stimulant effects. Methods: Sensitization was induced in DBA/2 $\mathrm{J}$ mice by administering ethanol (2 $\mathrm{g} / \mathrm{kg})$ intraperitoneally (i.p.) before four activity trials. Control groups were given saline (12.5 ml/kg i.p.) before each activity trial. Subsequently, the effects of two NMDA receptor antagonists, MK-801 and ifenprodil, and two non-NMDA glutamate receptor antagonists, DNQX and GYKI 52466, were assessed on expression of the sensitized locomotor response. Results: MK-801 reduced the stimulant effects of ethanol and completely prevented expression of sensitization at doses exceeding $0.075 \mathrm{mg} / \mathrm{kg}$. In contrast, although ifenprodil also reduced the stimulant effects of ethanol, the antagonist did not alter expression of sensitization. Non-NMDA glutamate antagonists were more consistent in their effects on sensitization. DNQX reduced the magnitude of the sensitized response at a low dose that did not alter the stimulant effects of ethanol. The more selective AMPA antagonist GYKI 52466 reduced the stimulant effects of ethanol and completely blocked expression of sensitization. Conclusions: The results provide initial evidence to suggest that both NMDA and non-NMDA glutamate receptors play a role in expression of sensitization to ethanol. Additional research will be required to elucidate the mechanisms underlying differences in the efficacy of glutamate antagonists.
\end{abstract}

J. Broadbent $(\bowtie) \cdot$ K. M. Kampmueller · S. A. Koonse Department of Psychiatry,

Division of Substance Abuse, University of Michigan, 205 Zina Pitcher Place, Ann Arbor, MI 48109-0720, USA e-mail: broadben@umich.edu

Fax: +1-419-8188646
Keywords Sensitization - Locomotor activity - Ethanol . Glutamate $\cdot \mathrm{DBA} / 2 \mathrm{~J}$ mice

\section{Introduction}

Behavioral sensitization (defined as a progressive increase in the effect of a drug following repeated administration) has been proposed to play a central role in drug addiction (Robinson and Berridge 1993, 2000). Several lines of evidence support this proposal. First, sensitization develops to the locomotor stimulant effects of a number of abused drugs such as psychostimulants and opiates (Vanderschuren and Kalivas 2000). Moreover, the sensitized response is persistent (Babbini et al. 1975; Shuster et al. 1977; Paulson et al. 1991) and is thought to enhance the incentive-motivational effects of drugs, and stimuli associated with them (Lett 1989; Shippenberg and Heidbreder 1995; Harmer and Phillips 1999; Taylor and Horger 1999). Finally, only those drugs that produce sensitization are effective in reinstating drug-seeking behavior (De Vries et al. 1998). These studies link sensitization to drug-taking and suggest that treatments that prevent expression of sensitization may reduce the probability of relapse.

Evidence is now available to demonstrate that sensitization also develops to the locomotor stimulant effects of ethanol (Phillips et al. 1994; Broadbent and Harless 1999; Broadbent and Weitemier 1999; Itzhak and Martin 2000; Fish et al. 2002). This response appears to be unrelated to changes in ethanol's sedative effects (Phillips et al. 1996), suggesting increased activity levels are attributable to the development of sensitization rather than tolerance. Sensitization to ethanol is relatively long lasting (Lessov and Phillips 1998; Fish et al. 2002) and is correlated with preference for ethanol in the HAP and LAP selected lines of mice (Grahame et al. 2000). These studies, and evidence that alcoholics and the sons of alcoholics show sensitization to the stimulant effects of ethanol (Newlin and Thomson 1991, 1999), suggest that 
sensitization to ethanol may play a significant role in alcohol abuse (however, see Cunningham et al. 2002).

Despite evidence that robust sensitization develops to ethanol, relatively little is known about the neural processes underlying this neuroadaptive response. Ethanol is known to act at both $N$-methyl-D-aspartate (NMDA) and non-NMDA glutamate receptors (Faingold et al. 1998), receptors that play a significant role in neuronal plasticity and have been implicated in expression of sensitization to psychostimulants (Vanderschuren and Kalivas 2000). Moreover, cross-sensitization has been reported to occur between ethanol and psychostimulants (Manley and Little 1997; Itzhak and Martin 1999; however see Fish et al. 2002). Hence, it seems likely that glutamate receptors may play a role in expression of sensitization to ethanol. The present experiments were designed to investigate the role of both NMDA and nonNMDA glutamate receptors in expression of sensitization to the stimulant effects of ethanol. DBA/2 J mice were used as subjects since they rapidly develop robust sensitization to ethanol. DBA/2 J mice have traditionally been characterized as "alcohol-avoiders", raising questions regarding the relevance of studying sensitization in these mice. However, aversion to the taste of ethanol appears to account, in large part, for the reluctance of this strain to drink ethanol solutions (Belknap et al. 1977).

A series of experiments examined the effects of two NMDA antagonists, MK-801 (dizocilpine) and ifenprodil, and two non-NMDA glutamate receptor antagonists, DNQX and GYKI 52466, on expression of behavioral sensitization to the locomotor stimulant effects of ethanol. Activity cages containing photobeams were used to measure sensitization. MK-801 has frequently been used to assess the role of NMDA receptor blockade on expression of sensitization to psychostimulants. Examining the effects of the non-competitive NMDA receptor antagonist ifenprodil was of particular interest due to its selectivity for the NR2B sub-unit of the NMDA receptor (Williams 2001), the subunit that has been strongly implicated in the actions of ethanol. The non-NMDA glutamate antagonists DNQX and GYKI 52466 have differential effects on AMPA and kainate receptors, with GYKI 52466 having more selective actions on AMPA receptors than DNQX (Wilding and Huettner 1995; Bleakman et al. 1996). Hence, by examining the effects of these antagonists, the relative roles of AMPA and kainate receptors in expression of sensitization to ethanol may be revealed.

\section{Materials and methods}

Subjects

Six-week-old male DBA/2 J mice (Jackson Laboratory, Bar Harbor, Maine) were housed in groups of four with food and water freely available. Subjects were allowed to habituate to the colony for a minimum of 12 days before the start of experiments. Animals were maintained on a 12-h/12-h light/dark cycle with lights on at
0600 hours. The NIH "Principles of laboratory animal care" were followed in conducting these studies.

\section{Apparatus}

The locomotor activity of individual animals was measured in one of eight activity cages made of clear Plexiglas $(28.5 \times 23 \times 20.5 \mathrm{~cm}$; Med Associates, East Fairfield, VT). Activity was monitored by eight infrared photobeams placed at approximately 3-cm intervals, $2 \mathrm{~cm}$ above the Plexiglas floor. Activity cages were placed inside sound- and light-attenuating chambers. Ventilation fans provided a constant background noise. A Gateway computer interfaced with the activity cages measured activity levels. Activity cages were cleaned after each trial.

\section{Drugs}

(+) MK-801 hydrogen maleate [dizocilpine maleate, (5-methyl10,11-dihydro-5H-dibenzo[a,d]cyclohepten-5,10-imine); RBI, Natick, MA] and ifenprodil tartrate ( $\alpha$-[4-hydroxyphenyl]- $\beta$-methyl-4benzyl-1-piperidineethanol tartrate; Sigma-Aldrich, St. Louis, MO) were dissolved in $0.9 \%$ saline. DNQX (6,7-dinitroquinoxaline-2,3dione; RBI) was placed in $0.9 \%$ saline and shaken immediately before administration to produce a suspension. GYKI 52466 hydrochloride [1-(4-aminophenyl)-4-methyl-7,8-methylenedioxy5H-2,3-benzodiazepine hydrochloride; Sigma-Aldrich] was dissolved in a small volume of $0.1 \mathrm{M}$ hydrochloric acid, neutralized with $0.1 \mathrm{M}$ sodium hydroxide and made up to volume with $0.9 \%$ saline. MK-801, ifenprodil and DNQX were administered i.p. $30 \mathrm{~min}$ before the test. GYKI 52466 was administered i.p. 5 min before the test. Antagonist solutions were prepared on the day of the test and administered i.p. in a volume of $10 \mathrm{ml} / \mathrm{kg}$. Ethanol $(2 \mathrm{~g} /$ $\mathrm{kg}, 20 \% \mathrm{v} / \mathrm{v}$ in $0.9 \%$ saline) was administered i.p. in a volume of $12.5 \mathrm{ml} / \mathrm{kg}$ immediately before trials.

\section{Procedure}

Subjects were transported to the laboratory at least $1 \mathrm{~h}$ before the start of activity measurement. Trials for MK-801 and DNQX experiments were conducted at 48-h intervals while trials for ifenprodil and GYKI 52466 experiments were conducted on Mondays, Wednesdays and Fridays. This difference in procedure did not alter acquisition of sensitization. The 5-min trials were run at approximately the same time of day for each subject. Each experiment consisted of a habituation trial, a minimum of four activity trials (induction phase) and a number of test trials. The habituation trial served to reduce the stress and novelty associated with exposure to the activity cages, and injection and handling procedures. Immediately before this trial, mice were weighed and then received an i.p. injection of $0.9 \%$ saline. Following the habituation trial, animals were assigned to one of two experimental groups (saline or ethanol) such that groups had similar mean activity levels, and the home and test cages were counter-balanced across groups.

Following the habituation trial, subjects received four activity trials immediately before which animals were weighed and given an injection of saline or ethanol $(2 \mathrm{~g} / \mathrm{kg})$. Following the fourth activity trial, saline and ethanol groups were sub-divided. Mice were allocated to sub-groups so that activity levels on the last activity trial were similar across sub-groups. Test trials were conducted $48 \mathrm{~h}$ after the last activity trial. Test trials lasted $30 \mathrm{~min}$ with the exception of tests in the GYKI 52466 experiment when 20min tests were conducted. GYKI 52466 is a fast-acting drug, therefore, the majority of its effects can be observed over a shorter period (Chapman et al. 1991). Mice received two i.p. injections before test trials. The first injection was of saline or a dose of the antagonist. The second injection, given immediately before the test, was $2 \mathrm{~g} / \mathrm{kg}$ of ethanol for all animals except where noted below. The test trial permitted assessment of the development of sensi- 
tization in the ethanol control group and the effects of the antagonists on both the acute stimulant response to ethanol (saline groups) and sensitization (ethanol groups).

Following the test trial, mice in the DNQX, ifenprodil and GYKI 52466 experiments received two additional 5-min activity trials before which animals were injected with saline or ethanol according to their training group designation. The interval between trials was $48 \mathrm{~h}$. A second test was conducted $48 \mathrm{~h}$ after the last activity trial. The second test in the DNQX experiment was identical to the first test with the exception that mice that received $25 \mathrm{mg} / \mathrm{kg}$ and $50 \mathrm{mg} / \mathrm{kg}$ DNQX previously were given $75 \mathrm{mg} / \mathrm{kg}$ and $100 \mathrm{mg} / \mathrm{kg}$ DNQX, respectively. Similarly, ifenprodil groups that received $1.0 \mathrm{mg} / \mathrm{kg}$ and $2.5 \mathrm{mg} / \mathrm{kg}$ of the antagonist on the first test received $5.0 \mathrm{mg} / \mathrm{kg}$ and $7.5 \mathrm{mg} / \mathrm{kg}$, respectively, on the second test. The low-dose ifenprodil groups were not assessed on the second test. The second test in the GYKI 52466 experiment assessed the effect of the antagonist on baseline activity levels of the four saline-treated control groups. Hence, treatment on this test was identical to that on the first test with the exception that saline was injected immediately before the test instead of ethanol.

Blood ethanol measurement

Blood ethanol levels were measured immediately after behavioral testing by removing $2-3 \mathrm{~mm}$ of the end of the tail and collecting approximately $40 \mu \mathrm{l}$ of blood in a capillary tube containing heparin. Following centrifugation, the supernatent was drawn off and stored at $-20^{\circ} \mathrm{C}$ until measurement of ethanol levels on an Analox GL5 electrochemical analyzer (Lunenburg, MA).

Data analysis

All data were initially analyzed using analysis of variance (ANOVA; Systat, SPSS Inc.) to determine the overall pattern of effects produced by antagonists. Changes in sensitization caused by individual doses of antagonists were determined by comparing activity levels of the ethanol control group (i.e., the 0 ethanol group) with those of ethanol groups that received the antagonist, and by comparing activity levels of saline and ethanol groups treated with the same dose of the antagonist on the test using ANOVA followed by Tukey HSD tests when appropriate. Effects of the antagonists on ethanol's acute stimulant effects were determined by comparing activity levels of the saline control group (i.e., the 0 saline group) with those of saline groups treated with the antagonist. Probability levels of 0.05 or less were considered significant. The number of animals in experimental groups ranged from 10 to 16 (see figure legends).

\section{Results}

NMDA receptor blockade

MK-801

Experiment 1. The first study examined the effects of MK-801 on expression of sensitization. Significant increases in activity were observed in the ethanol-treated group over the four activity trials. Mean $( \pm$ SEM) scores were $151 \pm 5,180 \pm 5,198 \pm 7$ and $202 \pm 8$ for trials $1-4$, respectively. In contrast, activity of the saline group decreased somewhat over trials: mean $( \pm$ SEM $)$ activity scores were $83 \pm 4,68 \pm 4,64 \pm 4$ and $57 \pm 3$ for trials $1-4$, respectively. A two-way ANOVA revealed a main effect of trial treatment (saline or ethanol) $\left(F_{1,94}=376, P<0.01\right)$, of trial $\left(F_{3,282}=6.3, P<0.01\right)$ and a trial treatment $\times$ trial interaction $\left(F_{3,282}=46, P<0.01\right)$. A one-way ANOVA used to examine changes in activity of the ethanol group over trials indicated a significant effect of trial $\left(F_{3,141}=31.1\right.$, $P<0.01$ ), suggesting within-group sensitization developed. Sensitization was also evident when the animals were separated into sub-groups for the test: one-way ANOVAs conducted on each sub-group showed a significant main effect of trial ( $F$ values $=8.4-13.3, P<0.01$ ).

The results of the 30-min sensitization test are shown in Fig. 1 (left panel). Between-group sensitization was observed in that activity of the ethanol control group (0 ethanol) was higher than that of the saline control group (0 saline). Both doses of MK-801 suppressed activity levels of the ethanol groups so that the activity of these groups was only slightly higher than those of the saline controls (e.g., 0.15 saline vs 0.15 ethanol). It should be noted, however, that MK-801 also decreased activity levels of the saline control groups. A two-way ANOVA indicated a main effect of trial treatment (saline or ethanol; $\left.F_{1,90}=11.4, P<0.01\right)$ and of MK-801 $\left(F_{2,90}=29.4\right.$, $P<0.01)$. The trial treatment $\times$ MK-801 interaction was not significant. Planned comparisons across pairs of saline and ethanol groups treated with the same dose of the antagonist with one-way ANOVAs (e.g., 0 saline vs 0 ethanol) revealed differences between the 0 saline and 0 ethanol groups $\left(F_{1,30}=13.6, P<0.01\right)$, indicating significant between-group sensitization developed in the control groups. In contrast, activity levels of the ethanol groups treated with MK-801 did not differ from their saline control groups, suggesting suppression of sensitization. This result was supported by planned comparison of activity levels of the ethanol groups with a one-way ANOVA that showed a main effect of MK-801 $\left(F_{2,45}=20.2, P<0.01\right)$ and differences between the ethanol control group and both antagonist-treated groups $(P<0.01)$. Planned comparison of activity levels across the three saline control groups with a one-way ANOVA revealed a main effect of MK-801 $\left(F_{2,45}=9.9, P<0.01\right)$, indicating the antagonist reduced the stimulant effects of ethanol. Follow-up analysis with Tukey tests revealed that both doses of MK-801 significantly decreased activity levels relative to the 0 saline control group $(P<0.01)$.

Changes in activity levels across the 30-min test were also analyzed in this (and all subsequent) experiments. These analyses did not reveal substantial differences in the effects of antagonists from those represented by the 30-min means and, therefore, are not described.

Experiment 2. Lower doses of MK-801 were examined in experiment 2 in an attempt to minimize the suppression of ethanol's stimulant effects observed in the previous experiment. Data for one subject on the second activity trial were lost due to a computer malfunction. Significant sensitization, similar to that reported in experiment 1 , was observed in the ethanol-treated groups across trials.

The effects of low doses of MK-801 on expression of sensitization are shown in Fig. 1 (right panel). Sensitization was apparent between the ethanol (0 ethanol) and saline ( 0 saline) control groups in the $30-$ min test. 


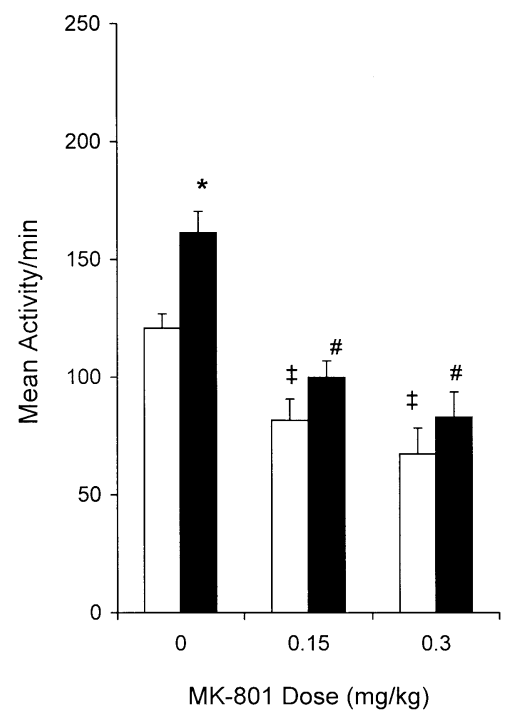

Fig. 1 Effect of the $N$-methyl-D-aspartate (NMDA) antagonist MK801 on expression of sensitization to ethanol. Activity levels are expressed as mean activity counts per minute (+SEM). Mice received saline or a dose of MK-801 30 min before the 30-min test. All animals were also injected with ethanol $(2 \mathrm{~g} / \mathrm{kg})$ immediately before the test. Open and closed bars indicate mice treated with saline or ethanol, respectively, on activity trials. The left panel

Moreover, comparison of saline and ethanol groups treated with the same dose of MK-801 revealed ethanol groups had consistently higher activity levels, suggesting expression of sensitization. In contrast to experiment 1 , low doses of the antagonist did not alter the stimulant effects of ethanol in that the activity of the saline control groups (i.e., 0.0375 saline and 0.075 saline) did not differ from the 0 saline group. Analysis of the data in a two-way ANOVA revealed only a main effect of trial treatment $\left(F_{1,90}=52.6, P<0.01\right)$. Planned comparison of saline and ethanol groups given the same dose of the antagonist by one-way ANOVAs indicated significant sensitization in each ethanol group $(F$ values $=5.2-39.6, P<0.05)$. Planned comparison of activity levels across ethanol groups by a one-way ANOVA revealed a trend towards increased activity levels in the antagonist-treated groups $(P=0.08)$. MK-801 did not alter the stimulant effects of ethanol: planned comparison with a one-way ANOVA did not indicate changes in the activity levels of saline groups $(P>0.05)$.

\section{Ifenprodil}

Experiment 3. The effects of a second NMDA antagonist were examined in this experiment. As expected, animals repeatedly exposed to ethanol on trials 1-4 showed increasing activity levels across trials. Significant between-group sensitization was observed in all sub-groups on the 30-min test in that ethanol groups had higher

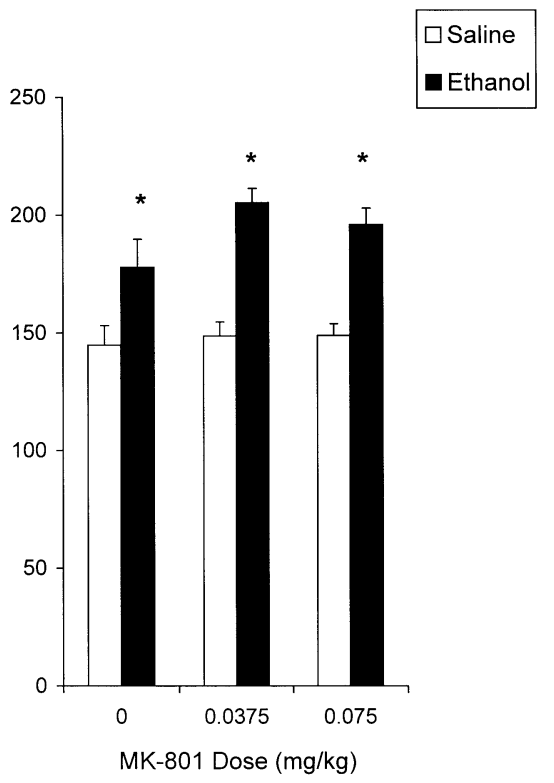

shows the effects of MK-801 in experiment 1 ( $n=16$ per group). Lower doses of the antagonist were administered in experiment 2 (right panel, $n=16$ per group). *Significant differences from saline groups treated with the same dose of the antagonist $(P<0.05)$. $\$$ Significant differences from the 0 saline group $(P<0.05)$. \#Significant differences from the 0 ethanol group $(P<0.05)$

activity levels than saline groups (Fig. 2, left panel). A two-way ANOVA confirmed this finding in that only the main effect of trial treatment (saline or ethanol) $\left(F_{1,88}=54.5, \quad P<0.01\right)$ was significant. Comparison of saline and ethanol groups treated with the same dose of the antagonist by one-way ANOVAs indicated that ethanol groups consistently had significantly higher activity levels $(F$ values $=10.5-26.4, P<0.01)$. Planned comparison of ethanol groups with a one-way ANOVA did not reveal differences in activity levels $(P>0.05)$. Comparison of ifenprodil-treated saline groups with their control group (0 saline) using a one-way ANOVA revealed that ifenprodil did not alter ethanol-stimulated activity $(P>0.05)$.

Higher doses of ifenprodil were examined on a second test by administering $5.0 \mathrm{mg} / \mathrm{kg}$ and $7.5 \mathrm{mg} / \mathrm{kg}$, respectively, to the groups treated with $1.0 \mathrm{mg} / \mathrm{kg}$ and $2.5 \mathrm{mg} / \mathrm{kg}$ of ifenprodil on test 1 (Fig. 2, right panel). The 0 groups were again pre-treated with saline. Two activity trials separated the two tests. Mean activity levels $( \pm$ SEM) for saline sub-groups ranged from $58 \pm 9$ to $83 \pm 6$ on these trials, while activity levels of the ethanol sub-groups varied from $194 \pm 18$ to $253 \pm 20$. Sensitization was apparent on the test despite administration of doses of ifenprodil that decreased activity levels of control groups. These results were confirmed using a two-way ANOVA conducted on the 30-min test activity means. Significant main effects of trial treatment $\left(F_{1,66}=35.3, P<0.01\right)$ and of ifenprodil $\left(F_{2,66}=6.5, P<0.01\right)$ were found but no trial treatment $\times$ ifenprodil interaction. Comparison of saline 


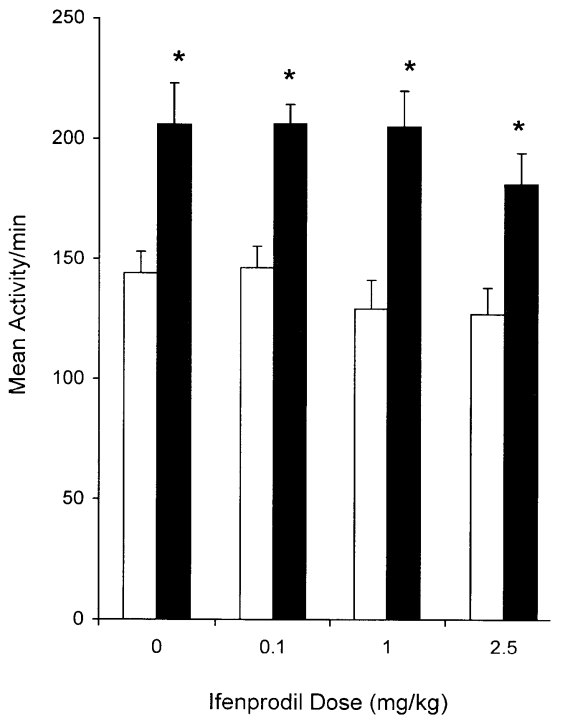

Fig. 2 Effect of the $N$-methyl-D-aspartate (NMDA) antagonist ifenprodil on expression of sensitization to ethanol. Activity levels are expressed as mean activity counts per minute (+SEM). Mice received saline or a dose of ifenprodil $30 \mathrm{~min}$ before the 30 -min test. All animals were also injected with ethanol $(2 \mathrm{~g} / \mathrm{kg})$ immediately before the test. Open and closed bars indicate mice

and ethanol groups treated with the same dose of the antagonist by one-way ANOVAs indicated that ethanol groups consistently had significantly higher activity levels $(F$ values $=4.7-19.6, \quad P<0.05)$. A one-way ANOVA followed by Tukey tests on the saline control groups revealed that ifenprodil significantly decreased ethanolstimulated activity at both $5.0 \mathrm{mg} / \mathrm{kg}$ and $7.5 \mathrm{mg} / \mathrm{kg}$ $\left(F_{2,33}=11.4, P<0.01\right)$. In contrast, ifenprodil did not alter the activity levels of ethanol groups $(P>0.05)$.

Analysis of blood samples taken approximately $36 \mathrm{~min}$ after ethanol injection (mean $=36.4 \pm 0.4 \mathrm{~min}$ ) on the second test revealed mean blood ethanol levels of $143.5 \pm 6 \mathrm{mg} / \mathrm{dl}$ across all animals (mean values \pm SEM were $147.3 \pm 12,143.5 \pm 14,145.7 \pm 15,131.3 \pm 13,161.9 \pm 13$ and $131.9 \pm 14$ for the 0 saline, 5 saline, 7.5 saline, 0 ethanol, 5 ethanol and 7.5 ethanol groups, respectively). A two-way ANOVA (trial treatment $x$ ifenprodil) did not reveal differences in blood ethanol levels between ifenprodil-treated animals and untreated controls ( $F$ values $<1.0$ ).

Non-NMDA glutamate receptors

\section{$D N Q X$}

Experiment 4. The effects of the non-NMDA glutamate receptor antagonist DNQX on expression of sensitization were examined in experiment 4. One subject was eliminated from the experiment due to ill health on arrival. Development of sensitization, similar to that described in previous experiments, was evident in the

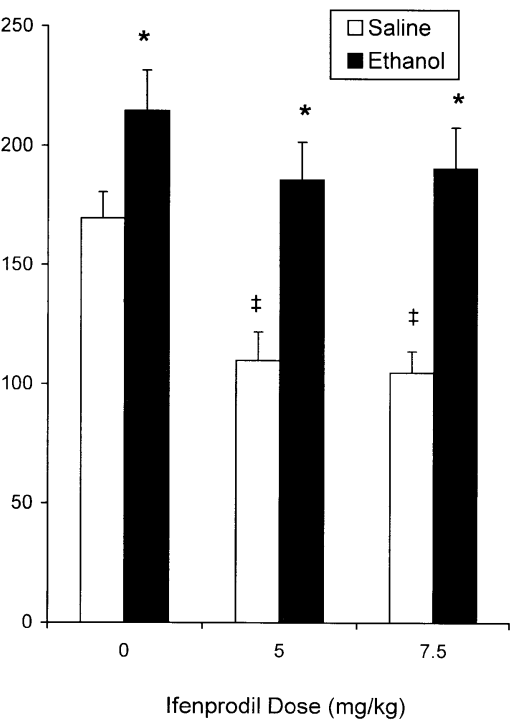

treated with saline or ethanol, respectively, on activity trials. The left panel shows the effects of ifenprodil on test 1 ( $n=12$ per group). Higher doses of the antagonist were administered on test 2 (right panel, $n=12$ per group). The meaning of symbols is described in the legend of Fig. 1

ethanol groups with activity levels rising over activity trials.

The results of the 30-min sensitization test are shown in Fig. 3 (left panel). Differences in activity levels of saline and ethanol control groups indicated development of between-group sensitization. Both doses of DNQX tended to decrease the magnitude of sensitization, but did not eliminate it. Finally, neither dose of DNQX altered the stimulant response to ethanol as shown by the similar activity levels of the saline control groups. Analysis of the test data by a two-way ANOVA showed a main effect of trial treatment $\left(F_{1,89}=43.1, \quad P<0.01\right)$ and of DNQX $\left(F_{2,89}=3.6, P<0.05\right)$. The trial treatment $\times$ DNQX interaction was not significant $(P=0.16)$. Planned comparison of activity levels of control and ethanol-treated groups given the same dose of the antagonist by one-way ANOVAs indicated that all groups given ethanol on activity trials had higher activity levels than their saline control groups $(F$ values $=7.8-28.7, P<0.05)$. Planned comparisons of the effects of DNQX on activity levels of ethanol groups by a one-way ANOVA revealed a significant effect of DNQX $\left(F_{2,45}=3.9, P<0.05\right)$. Followup analysis with Tukey tests indicated a significant decrease in activity levels of the 25 ethanol group relative to the ethanol control group (i.e., 0 ethanol; $P=0.02$ ). While $50 \mathrm{mg} / \mathrm{kg}$ DNQX tended to decrease activity, this effect did not quite reach significance $(P=0.14)$. A oneway ANOVA indicated that DNQX did not alter activity levels of saline control groups and therefore did not affect the stimulant effects of ethanol $(P>0.05)$.

To determine whether larger doses of DNQX would block expression of sensitization, doses of $75 \mathrm{mg} / \mathrm{kg}$ and $100 \mathrm{mg} / \mathrm{kg}$ were administered before the second test to 


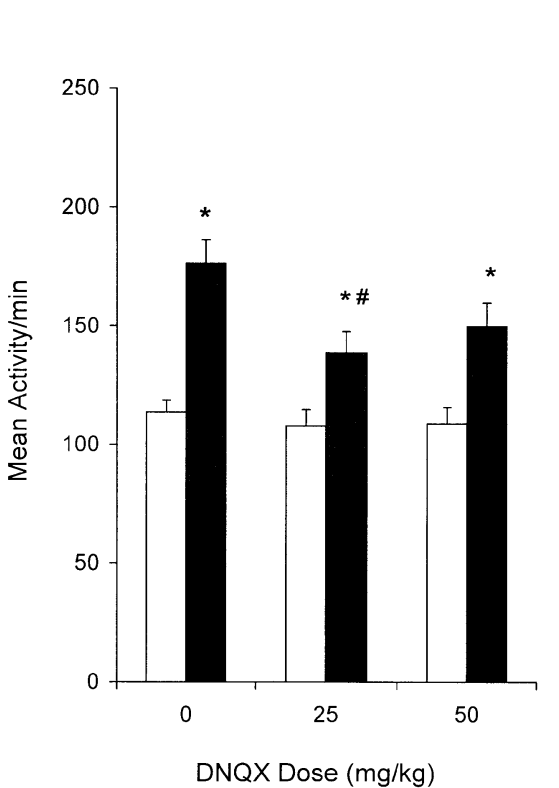

Fig. 3 Effect of the non- $N$-methyl-D-aspartate (NMDA) antagonist DNQX on expression of sensitization to ethanol. Activity levels are expressed as mean activity counts per minute (+SEM). Mice received saline or a dose of DNQX 30 min before the 30-min test. All animals were also injected with ethanol $(2 \mathrm{~g} / \mathrm{kg})$ immediately before the test. Open and closed bars indicate mice treated with

groups that had previously received $25 \mathrm{mg} / \mathrm{kg}$ and $50 \mathrm{mg} /$ $\mathrm{kg}$, respectively (Fig. 3, right panel). Two activity trials were conducted between the two tests as a wash-out period. Activity levels on these trials were similar to those observed on the last activity trial before the first test (mean activity levels of ethanol groups ranged from $187.5 \pm 15$ to $214 \pm 12$, while mean activity of saline groups ranged from $60 \pm 8$ to $76 \pm 6$ ). Interestingly, DNQX at the higher doses again decreased but did not eliminate sensitization. However, the antagonist also decreased the stimulant response to ethanol at higher doses in that DNQX decreased activity levels of saline groups. These results were confirmed using a two-way ANOVA that indicated a main effect of trial treatment $\left(F_{1,89}=37.9\right.$, $P<0.01)$ and of DNQX $\left(F_{2,89}=21.8, P<0.01\right)$ but a nonsignificant interaction. Planned comparison of activity levels across pairs of groups (e.g. 0 saline vs 0 ethanol) by one-way ANOVAs showed all ethanol groups had higher activity levels than saline control groups $(F$ values $=6.9$ $18.9, P<0.05)$. However, planned comparison of activity levels of ethanol groups by a one-way ANOVA indicated that DNQX reduced activity levels at both doses $\left(F_{2,45}=13.6, P<0.01\right)$. Similarly, activity levels of saline groups were also reduced $\left(F_{2,44}=8.4, P<0.01\right)$.

\section{GYKI 52466}

Experiment 5. The effects of an additional non-NMDA glutamate antagonist were examined in this experiment. One mouse died after the third trial. The data for this

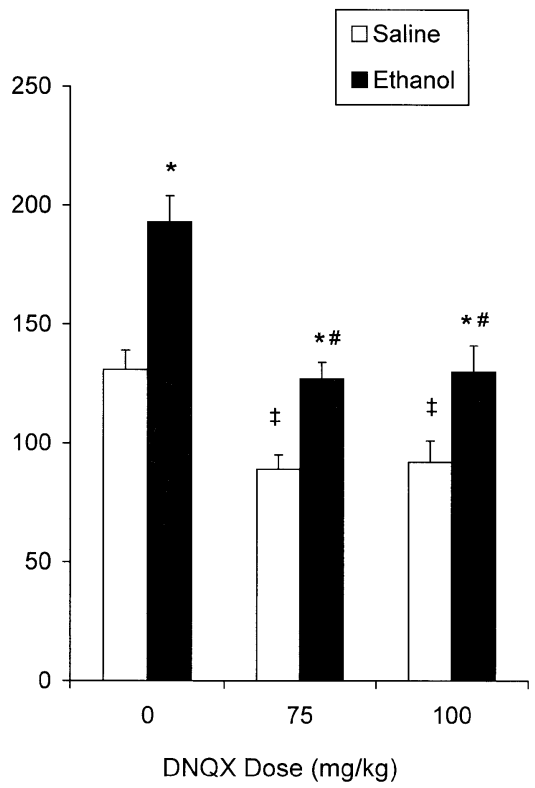

saline or ethanol, respectively, on activity trials. The left panel shows the effects of DNQX on test $1(n=15-16$ per group). Higher doses of the antagonist were administered on test 2 (right panel, $n=15-16$ per group). The meaning of symbols is described in the legend of Fig. 1

animal were removed from the experiment. Due to a computer error, test data were lost for eight animals. Analysis of changes in activity levels of ethanol groups demonstrated that significant sensitization occurred across trials, as seen in previous experiments.

The results of the 20-min test are displayed in Fig. 4. The higher doses of GYKI 52466 decreased the stimulant effects of ethanol as shown by decreases in the activity levels of the saline groups. Moreover, the antagonist also prevented expression of sensitization: activity levels of the ethanol and saline groups were similar after administration of $10.0 \mathrm{mg} / \mathrm{kg}$. A two-way ANOVA (trial treatment $\times$ GYKI 52466) confirmed these findings in that a significant main effect of trial treatment $\left(F_{1,79}=37.6, \quad P<0.01\right)$, of GYKI $52466 \quad\left(F_{3,79}=26.4\right.$, $P<0.01)$ and trial treatment $\times$ GYKI 52466 interaction $\left(F_{3,79}=2.8, P<0.05\right)$ were found. Comparison of saline and ethanol groups treated with the same dose of the antagonist by one-way ANOVAs demonstrated significant sensitization in the groups receiving $0\left(F_{1,20}=9.3\right.$, $P<0.01), \quad 2.5 \quad\left(F_{1,20}=12.5, \quad P<0.01\right)$ and $5.0 \mathrm{mg} / \mathrm{kg}$ $\left(F_{1,20}=20.6, P<0.01\right)$ but not $10.0 \mathrm{mg} / \mathrm{kg}$ GYKI 52466 $(P>0.05)$. Analysis of the effects of the antagonist on activity levels of ethanol groups with a one-way ANOVA and Tukey tests revealed significant effects only at the highest dose $\left(F_{3,39}=14.2, P<0.01\right)$. In contrast, comparison of activity levels of saline groups by a one-way ANOVA indicated that $5 \mathrm{mg} / \mathrm{kg}$ and $10 \mathrm{mg} / \mathrm{kg}$ GYKI 52466 decreased the acute stimulant effects of ethanol $\left(F_{3,40}=14.6, P<0.01\right)$. 
Fig. 4 Effect of the non- $N$ methyl-D-aspartate (NMDA) antagonist GYKI 52466 on expression of sensitization to ethanol. Activity levels are expressed as mean activity counts per minute $(+\mathrm{SEM})$. Mice received vehicle or a dose of GYKI $524665 \mathrm{~min}$ before the 20-min test. All animals were also injected with ethanol $(2 \mathrm{~g} / \mathrm{kg})$ immediately before the test. Open and closed bars indicate mice treated with saline or ethanol, respectively, on activity trials $(n=10-11$ per group). The meaning of symbols is described in the legend of Fig. 1

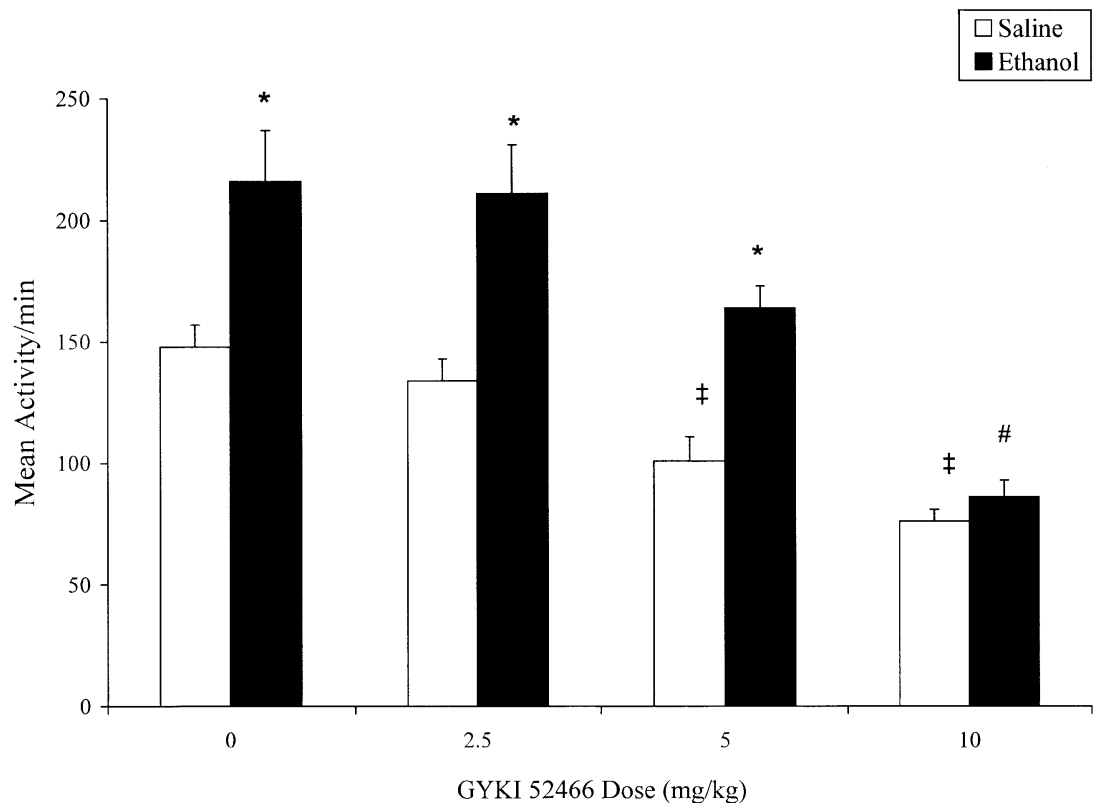

Blood ethanol levels measured approximately $33 \mathrm{~min}$ after injection of ethanol (mean $=32.8 \pm 0.6)$ indicated an overall mean level of $192.1 \pm 3 \mathrm{mg} / \mathrm{dl}$ (mean values \pm SEM were $204.6 \pm 9,192.1 \pm 7,192.9 \pm 7$ and $209.5 \pm 8$ for the 0 , $2.5,5.0$ and 10 saline groups, while the values were $174.9 \pm 12,178.1 \pm 11,186.6 \pm 12$ and $195.9 \pm 10$ for the 0 , 2.5, 5.0 and 10 ethanol groups, respectively). Surprisingly, animals that received ethanol on trials had slightly lower blood ethanol levels (mean of $184.1 \pm 5 \mathrm{mg} / \mathrm{dl}$ ) than mice treated with saline on trials (mean of $199.6 \pm 4 \mathrm{mg}$ / dl). Analysis of blood ethanol levels in a two-way ANOVA indicated a main effect of trial treatment $\left(F_{1,83}=5.6, P<0.05\right)$. In contrast, GYKI 52466 did not have a significant impact on blood ethanol levels: neither the main effect of GYKI 52466 nor the trial treatment $\times$ GYKI 52466 interaction was significant.

The effects of GYKI 52466 on baseline activity levels were examined on a second test by treating the four saline control groups with GYKI 52466 in the absence of ethanol. Two activity trials were conducted prior to this test. Activity levels on these trials were similar to previous trials: mean activity levels ranged from $57.7 \pm 10$ to $83.0 \pm 7$. Mean \pm SEM activity levels of groups given $0,2.5,5.0$ or $10.0 \mathrm{mg} / \mathrm{kg}$ GYKI 52466 and saline over the 20 -min test were $73.6 \pm 7,75.6 \pm 8,69.6 \pm 8$ and $53.1 \pm 5$, respectively ( $n=12$ per group). A one-way ANOVA did not reveal a significant effect of GYKI 52466 treatment $(P=0.13)$.

\section{Discussion}

The results of the present study indicate that NMDA and non-NMDA glutamate antagonists are able to prevent expression of sensitization to the stimulant effects of ethanol. However, substantial differences in the efficacy of antagonists, particularly the NMDA antagonists, were apparent. The first NMDA antagonist tested, MK-801, failed to alter expression of sensitization at low doses. However, higher doses of the antagonist were effective in blocking expression of sensitization in that activity levels of saline and ethanol groups treated with the same dose of the antagonist did not differ significantly. Doses of MK801 that prevented sensitization also blocked ethanol's stimulant effects: MK-801 decreased activity levels of saline control groups given ethanol on the test. It is possible, therefore, that MK-801's ability to block sensitization may reflect a non-specific suppression of locomotor activity. However, when given alone, MK-801 has been shown to stimulate rather than suppress locomotor activity in DBA/2J mice (Broadbent and Weitemier 1999) suggesting that MK-801 does not depress spontaneous locomotor activity per se. In contrast, the antagonist appears to specifically reduce ethanol's stimulant effects. Nevertheless, it could still be argued that the ability of MK-801 to block sensitization is secondary to decreases in the stimulant effects of ethanol. Reconciling the data with this hypothesis is problematic, however. For example, one would predict that blockade of ethanol's acute stimulant effects in both saline and ethanol groups would decrease activity levels of these groups by similar amounts. Thus, activity levels of ethanol groups would still exceed those of saline groups. In contrast, MK-801 had substantially greater effects on activity levels of ethanol groups, resulting in similar activity levels in saline and ethanol groups. Blockade of sensitization therefore appears to be superimposed on MK-801's effects on the acute stimulant properties of ethanol.

It has been suggested that MK-801 potentiates the effects of ethanol, effectively shifting ethanol's doseresponse curve to the left (Meyer and Phillips 2001). According to this hypothesis, combining MK-801 with a 
peak stimulant dose of ethanol would produce activity levels on the descending limb of ethanol's inverted Ushaped dose-response curve. While shifts in ethanol's dose-response curve may explain MK-801's ability to block the stimulant effects of ethanol, it is more difficult to explain the effects of MK-801 on sensitization in this way. If one assumes MK-801 produces similar shifts in the dose-response curves of control and sensitized groups, sensitized groups would still exhibit higher activity levels than non-sensitized controls, providing that MK-801 does not cause a 'floor' effect on activity levels of control groups. In contrast, control and sensitized groups treated with $0.15 \mathrm{mg} / \mathrm{kg}$ and $0.3 \mathrm{mg} / \mathrm{kg}$ MK801 had similar activity levels and did not appear to show a 'floor' effect. Hence, MK-801 suppressed activity levels of sensitized groups to a greater extent than nonsensitized groups. One scenario that could explain the greater effect of MK-801 on these groups is if sensitization to ethanol also causes a shift to the left in ethanol's dose-response curve. Sensitization, combined with administration of MK-801, would then shift the doseresponse curve of sensitized groups further to the left than acutely treated control groups and produce lower activity levels in sensitized groups. However, preliminary data from this laboratory do not support this theory in that sensitization caused an upward rather than a leftward shift in ethanol's dose-response curve (Broadbent and Harless 1997). Finally, it is possible that the effects of MK-801 are rate dependent, resulting in greater suppression of the higher activity levels of sensitized groups. This is an inherent issue in sensitization studies that has received little attention. Additional research will be required to test this hypothesis.

The ability of MK-801 to block expression of sensitization may depend on its ability to reverse the effects of repeated ethanol administration at NMDA receptors. Long-term treatment with high ethanol doses has been reported to cause upregulation of NMDA activity, an effect that is blocked by administration of an NMDA antagonist (for review see Kumari and Ticku 2000). However, a recent study reported that ethanol-induced increases in MK-801 binding in Swiss Webster mice were not associated with sensitization (Quadros et al. 2002). Additional studies will be required to reconcile these findings with those of the current study.

The effects of a second NMDA antagonist, ifenprodil, were examined to further assess the role of NMDA receptors in expression of sensitization to ethanol. It was of particular interest to investigate the effects of ifenprodil since a close correlation exists between neurons that are sensitive to ethanol and those that are sensitive to ifenprodil (Lovinger 1995; Yang et al. 1996; Engblom et al. 1997). Surprisingly, although doses of ifenprodil were tested that produced similar decreases in the stimulant effects of ethanol to those caused by MK-801, ifenprodil did not alter the magnitude of the sensitized response. These findings indicate that blockade of ethanol's stimulant effects does not necessarily affect expression of sensitization.
Substantial differences in the ability of the two NMDA antagonists to alter expression of sensitization suggests that blockade of sensitization may depend on actions at specific binding sites on the NMDA receptor or on actions at particular receptor sub-units. MK-801 acts as an open channel blocker by binding to the phencyclidine (PCP) site within the ion channel of the receptor. In contrast, ifenprodil is thought to bind to a site located, in part, on the NR1 receptor sub-unit and to possess only weak open channel blocking properties (for review see Williams 2001). Further, whereas MK-801 is a non-selective antagonist of NMDA receptors (Monaghan and Larsen 1997), ifenprodil shows high specificity for receptors containing the NR2B sub-unit (Williams 1993) suggesting that receptors containing NR2B receptor sub-units are not critical for expression of sensitization.

Tests were also conducted with antagonists that preferentially block non-NMDA glutamate receptors. DNQX reduced expression of sensitization in that DNQX selectively decreased activity levels of sensitized groups. Higher doses of the antagonist produced non-selective effects decreasing sensitization and activity levels of control groups. Hence, despite a fourfold increase in dose, DNQX reduced but did not completely block expression of sensitization. Although blood ethanol levels were not measured in this experiment, doses of $25 \mathrm{mg} / \mathrm{kg}$ and $75 \mathrm{mg} / \mathrm{kg}$ did not alter blood ethanol levels in a previous study and therefore are unlikely to account for the effects of DNQX (Broadbent and Kampmueller, unpublished observations).

The selective AMPA antagonist GYKI 52466 (Paternain et al. 1995; Wilding and Huettner 1995; Bleakman et al. 1996; however see Steppuhn and Turski 1993) reduced expression of sensitization at $10 \mathrm{mg} / \mathrm{kg}$ such that activity levels of non-sensitized and sensitized groups did not differ. However, GYKI 52466 also reduced activity levels of control groups. As in the case of MK-801, the effects of GYKI 52466 on both sensitized and non-sensitized groups raises questions regarding the manner by which the antagonist blocks sensitization. Since GYKI 52466 did not alter spontaneous activity levels on the second test, the ability of the antagonist to block sensitization cannot be attributed to suppression of locomotor activity per se. Instead, the antagonist appears to preferentially reduce the stimulant effects of ethanol. However, the ability of GYKI 52466 to block the stimulant effects of ethanol does not appear to account for its effects on expression of sensitization since a similar decrease in ethanol's stimulant effects in sensitized and non-sensitized mice would still result in expression of sensitization, particularly since GYKI 52466 did not produce a floor effect on activity that would preclude detection of differences in activity levels of saline and ethanol-treated groups. Two pieces of evidence, albeit indirect, support the assertion that blockade of sensitization by GYKI 52466 is unrelated to its effects on the stimulant effects of ethanol. First, ifenprodil had similar effects on ethanol's stimulant effects to those seen with GYKI 52466, but in contrast to GYKI 52466, ifenprodil did not affect expression of 
sensitization, demonstrating that the two effects can be dissociated. Moreover, the ability of DNQX to reduce sensitization suggests that GYKI 52466 is also likely to alter expression of sensitization.

As GYKI 52466 is thought to have a greater affinity for AMPA than kainate receptors (Paternain et al. 1995; Wilding and Huettner 1995; Bleakman et al. 1996), the greater efficacy of GYKI 52466 relative to DNQX may indicate a more substantial role for AMPA receptors in sensitization. Alternatively, differences in efficacy may be due to the ability of antagonists to access central sites. While DNQX clearly produces central effects in that it changes gene expression when given systemically (Wang et al. 1994; Wang and McGinty 1996), it has been suggested that competitive AMPA antagonists such as DNQX have limited access to central sites (Bigge and Nikam 1997).

In summary, the present results suggest that both NMDA and non-NMDA receptors may play a role in expression of sensitization to ethanol, although the binding site, specific receptor subunits and receptor subtypes at which the antagonists act appear to substantially influence their ability to alter expression of sensitization. A large number of studies have also implicated glutamate receptors in expression of sensitization to psychostimulants, suggesting similarities in the mechanisms mediating expression of sensitization to psychostimulants and ethanol (for reviews see Wolf 1998; Vanderschuren and Kalivas 2000; Cornish and Kalivas 2001; Sripada et al. 2001). Additional studies will be required to confirm these similarities.

Acknowledgements The authors thank Dr. Christopher Cunningham for comments on an earlier version of the manuscript. Portions of these data were presented at the annual Research Society on Alcoholism meeting in Montreal, Canada, 2001. This work was supported by grants AA12090 and AA11066 to J.B. from NIAAA.

\section{References}

Babbini M, Gaiardi M, Bartoletti M (1975) Persistence of chronic morphine effects upon activity in rats 8 months after ceasing the treatment. Neuropharmacology 14:611-614

Belknap JK, Belknap ND, Berg JH, Coleman R (1977) Preabsorptive vs. postabsorptive control of ethanol intake in C57BL/6J and DBA/2J mice. Behav Genet 7:413-425

Bigge C, Nikam S (1997) AMPA receptor agonists, antagonists and modulators: their potential for clinical utility. Exp Opin Ther 7:1099-1114

Bleakman D, Ballyk BA, Schoepp DD, Palmer AJ, Bath CP, Sharpe EF, Woolley ML, Bufton HR, Kamboj RK, Tarnawa I, Lodge D (1996) Activity of 2,3-benzodiazepines at native rat and recombinant human glutamate receptors in vitro: stereospecificity and selectivity profiles. Neuropharmacology 35:16891702

Broadbent J, Harless WE (1997) Parametric analysis of sensitization to ethanol-stimulated locomotor activity in DBA/2J mice (abstract). Soc Neurosci 23:2389

Broadbent J, Harless WE (1999) Differential effects of GABA(A) and $\mathrm{GABA}(\mathrm{B})$ agonists on sensitization to the locomotor stimulant effects of ethanol in DBA/2J mice. Psychopharmacology 141:197-205
Broadbent J, Weitemier AZ (1999) Dizocilpine (MK-801) prevents the development of sensitization to ethanol in DBA/2J mice. Alcohol Alcohol 34:283-288

Chapman AG, Smith SE, Meldrum BS (1991) The anticonvulsant effect of the non-NMDA antagonists, NBQX and GYKI 52466, in mice. Epilepsy Res 9:92-96

Cornish JL, Kalivas PW (2001) Cocaine sensitization and craving: differing roles for dopamine and glutamate in the nucleus accumbens. J Addict Dis 20:43-54

Cunningham CL, Tull LE, Rindal KE, Meyer PJ (2002) Distal and proximal pre-exposure to ethanol in the place conditioning task: tolerance to aversive effect, sensitization to activating effect, but no change in rewarding effect. Psychopharmacology 160:414-424

De Vries TJ, Schoffelmeer AN, Binnekade R, Mulder AH, Vanderschuren LJ (1998) Drug-induced reinstatement of heroin- and cocaine-seeking behaviour following long-term extinction is associated with expression of behavioural sensitization. Eur J Neurosci 10:3565-3571

Engblom AC, Courtney MJ, Kukkonen JP, Akerman KE (1997) Ethanol specifically inhibits NMDA receptors with affinity for ifenprodil in the low micromolar range in cultured cerebellar granule cells. J Neurochem 69:2162-2168

Faingold CL, N'Gouemo P, Riaz A (1998) Ethanol and neurotransmitter interactions-from molecular to integrative effects. Prog Neurobiol 55:509-535

Fish EW, DeBold JF, Miczek KA (2002) Repeated alcohol: behavioral sensitization and alcohol-heightened aggression in mice. Psychopharmacology 160:39-48

Grahame NJ, Rodd-Henricks K, Li TK, Lumeng L (2000) Ethanol locomotor sensitization, but not tolerance correlates with selection for alcohol preference in high- and low-alcohol preferring mice. Psychopharmacology 151:252-260

Harmer CJ, Phillips GD (1999) Enhanced dopamine efflux in the amygdala by a predictive, but not a non-predictive, stimulus: facilitation by prior repeated D-amphetamine. Neuroscience 90:119-130

Itzhak Y, Martin JL (1999) Effects of cocaine, nicotine, dizocipline and alcohol on mice locomotor activity: cocaine-alcohol crosssensitization involves upregulation of striatal dopamine transporter binding sites. Brain Res 818:204-211

Itzhak Y, Martin JL (2000) Blockade of alcohol-induced locomotor sensitization and conditioned place preference in DBA mice by 7-nitroindazole. Brain Res 858:402-407

Kumari M, Ticku MK (2000) Regulation of NMDA receptors by ethanol. Prog Drug Res 54:151-189

Lessov CN, Phillips TJ (1998) Duration of sensitization to the locomotor stimulant effects of ethanol in mice. Psychopharmacology 135:374-382

Lett BT (1989) Repeated exposures intensify rather than diminish the rewarding effects of amphetamine, morphine, and cocaine. Psychopharmacology 98:357-362

Lovinger DM (1995) Developmental decrease in ethanol inhibition of $\mathrm{N}$-methyl-D-aspartate receptors in rat neocortical neurons: relation to the actions of ifenprodil. J Pharmacol Exp Ther 274:164-172

Manley SJ, Little HJ (1997) Enhancement of amphetamine- and cocaine-induced locomotor activity after chronic ethanol administration. J Pharmacol Exp Ther 281:1330-1339

Meyer PJ, Phillips TJ (2001) NMDA antagonism during chronic ethanol treatment. Alcohol Clin Exp Res 25:61A

Monaghan DT, Larsen H (1997) NR1 and NR2 subunit contributions to $N$-methyl-D-aspartate receptor channel blocker pharmacology. J Pharmacol Exp Ther 280:614-620

Newlin DB, Thomson JB (1991) Chronic tolerance and sensitization to alcohol in sons of alcoholics. Alcohol Clin Exp Res 15:399-405

Newlin DB, Thomson JB (1999) Chronic tolerance and sensitization to alcohol in sons of alcoholics: II. Replication and reanalysis. Exp Clin Psychopharmacol 7:234-243 
Paternain AV, Morales M, Lerma J (1995) Selective antagonism of AMPA receptors unmasks kainate receptor-mediated responses in hippocampal neurons. Neuron 14:185-189

Paulson PE, Camp DM, Robinson TE (1991) Time course of transient behavioral depression and persistent behavioral sensitization in relation to regional brain monoamine concentrations during amphetamine withdrawal in rats. Psychopharmacology 103:480-492

Phillips TJ, Dickinson S, Burkhart-Kasch S (1994) Behavioral sensitization to drug stimulant effects in C57BL/6J and DBA/2J inbred mice. Behav Neurosci 108:789-803

Phillips TJ, Lessov CN, Harland RD, Mitchell SR (1996) Evaluation of potential genetic associations between ethanol tolerance and sensitization in BXD/Ty recombinant inbred mice. $\mathrm{J}$ Pharmacol Exp Ther 277:613-623

Quadros I, Hipolide D, Frussa-Filho R, De Lucca E, Nobrega J, Souza-Formigoni M (2002) Resistance to ethanol sensitization is associated with increased NMDA receptor binding in specific brain areas. Eur J Pharmacol 442:55-61

Robinson TE, Berridge KC (1993) The neural basis of drug craving: an incentive-sensitization theory of addiction. Brain Res Brain Res Rev 18:247-291

Robinson TE, Berridge KC (2000) The psychology and neurobiology of addiction: an incentive-sensitization view. Addiction 95[Suppl 2]:S91-S117

Shippenberg TS, Heidbreder C (1995) Sensitization to the conditioned rewarding effects of cocaine: pharmacological and temporal characteristics. J Pharmacol Exp Ther 273:808-815

Shuster L, Yu G, Bates A (1977) Sensitization to cocaine stimulation in mice. Psychopharmacology 52:185-190

Sripada S, Gaytan O, Swann A, Dafny N (2001) The role of MK801 in sensitization to stimulants. Brain Res Brain Res Rev 35:97-114

Steppuhn KG, Turski L (1993) Modulation of the seizure threshold for excitatory amino acids in mice by antiepileptic drugs and chemoconvulsants. J Pharmacol Exp Ther 265:1063-1070
Taylor JR, Horger BA (1999) Enhanced responding for conditioned reward produced by intra-accumbens amphetamine is potentiated after cocaine sensitization. Psychopharmacology 142:3140

Vanderschuren LJ, Kalivas PW (2000) Alterations in dopaminergic and glutamatergic transmission in the induction and expression of behavioral sensitization: a critical review of preclinical studies. Psychopharmacology 151:99-120

Wang JQ, McGinty JF (1996) Acute methamphetamine-induced zif/268, preprodynorphin, and preproenkephalin mRNA expression in rat striatum depends on activation of NMDA and kainate/AMPA receptors. Brain Res Bull 39:349-57

Wang JQ, Daunais JB, McGinty JF (1994) Role of kainate/AMPA receptors in induction of striatal zif/268 and preprodynorphin mRNA by a single injection of amphetamine. Brain Res Mol Brain Res 27:118-126

Wilding TJ, Huettner JE (1995) Differential antagonism of alphaamino-3-hydroxy-5-methyl-4-isoxazolepropionic acid-preferring and kainate-preferring receptors by 2,3-benzodiazepines. Mol Pharmacol 47:582-587

Williams K (1993) Ifenprodil discriminates subtypes of the $N$ methyl-D-aspartate receptor: selectivity and mechanisms at recombinant heteromeric receptors. Mol Pharmacol 44:851859

Williams K (2001) Ifenprodil, a novel NMDA receptor antagonist: site and mechanism of action. Curr Drug Targets 2:285-298

Wolf ME (1998) The role of excitatory amino acids in behavioral sensitization to psychomotor stimulants. Prog Neurobiol 54:679-720

Yang X, Criswell HE, Simson P, Moy S, Breese GR (1996) Evidence for a selective effect of ethanol on $N$-methyl-Daspartate responses: ethanol affects a subtype of the ifenprodilsensitive $N$-methyl-D-aspartate receptors. J Pharmacol Exp Ther 278:114-124 